\title{
The Combined Effect of Photobiomodulation and Curcumin on Acute Skin Wound Healing in Rats
}

\author{
Abdollah Amini $^{\circledR}$, Hasan Soleimani $^{\circledR}$, Fatemehalsadat Rezaei $^{\circledR}$, Seyed Kamran Ghoreishi $^{\circledR}$, Sufan $^{\circledR}$ Chien $^{4^{\circledR}}$, \\ Mohammad Bayat ${ }^{1,4}$ \\ ${ }^{1}$ Department of Biology and Anatomical Sciences, School of Medicine, Shahid Beheshti University of Medical Sciences, \\ Tehran, Iran \\ ${ }^{2}$ College of Pharmacy, University of Kentucky, Lexington, KY, USA \\ ${ }^{3}$ Department of Statistics, University of Qom, Qom, Iran \\ ${ }^{4}$ Price Institute of Surgical Research, University of Louisville and Noveratech LLC of Louisville, Louisville, KY, USA.
}

\section{*Correspondence to \\ Mohammad Bayat, \\ PhD, Department of Biology and Anatomical Sciences, School of Medicine, Shahid Beheshti University of Medical Sciences, Tehran, Iran and Price Institute of Surgical Research, University of Louisville and Noveratech LLC of Louisville, Louisville, KY, USA. Tele/fax: +98 2122439976; Emails: mohbayat@sbmu.ac.ir, bayat_m@yahoo.com}

Published online February 23, 2021

\begin{abstract}
Introduction: Abnormal wound repair is a cause for considerable expense, as well as patient morbidity and mortality. Here, we investigated the combined impact of photobiomodulation (PBM) and curcumin on a rat experimental model of an acute skin wound.

Methods: A round full-thickness wound was created on the back of each rat. We divided the rats into the following four groups. Group one was the control group. Group two received pulse wave (PW) PBM at a dose of $890 \mathrm{~nm}, 80 \mathrm{~Hz}$, and $0.2 \mathrm{~J} / \mathrm{cm}^{2}$. Group 3 received $40 \mathrm{mg} / \mathrm{kg}$ curcumin by gastric gavage and group 4 were treated with PWPBM + curcumin. We measured the wound area on days 4,7 , and 15, and performed microbiological and tensiometric examinations.

Results: There was markedly improved wound contraction in the curcumin $(7.5 \pm 0.57 ; P=0.000)$, $\operatorname{PBM}(8.5 \pm 1.2 ; P=0.000)$, and $\mathrm{PBM}+$ curcumin $(14.5 \pm 4.3 ; P=0.002)$ groups relative to the control group $(25 \pm 6)$. PBM $(100 \pm 7.3 ; P=0.005)$, and PBM + curcumin $(98 \pm 6 ; P=0.005)$ groups meaningfully improved tensile strength relative to the control group (61 \pm 8.2$)$. On day 15 , the PBM $(10 \pm 5 ; P=0.000)$, curcumin $(14 \pm 4.5, P=0.000)$, and PBM + curcumin $(27.3 \pm 8.3 ; P=0.000)$ groups meaningfully decreased microbial flora relative to the control group $(95 \pm 6)$.

Conclusion: We concluded that the PBM and PBM + curcumin groups meaningfully accelerated wound healing of the acute skin wound in the rats. The results of the PBM group were statistically more effective than the curcumin alone and PBM + curcumin-treated groups.

Keywords: Wound healing, Curcumin, Therapies, Photobiomodulation, Low-level laser therapy, Wound closure techniques
\end{abstract}

\section{Introduction}

In 2012, there were approximately 312.9 million surgeries worldwide. ${ }^{1}$ Despite recent progress that has emphasized the importance of adjunct therapies in optimizing the repairing potential of skin, abnormal skin repair continues to cause considerable expense, and patient morbidity and mortality. ${ }^{2}$

Curcumin (diferuloylmethane) is an element of the Curcuma longa plant ${ }^{3}$ and it is considered to be one of the best medicinal herbs because of its anti-microbial, antiinflammatory, and antioxidant activities. ${ }^{4}$ The properties of curcumin have been investigated in different culture systems and animals. ${ }^{4}$ The World Health Organization (WHO) confirmed the everyday ingestion of curcumin as a food preservative. ${ }^{5}$ Curcumin has also been reported to have remarkable wound healing characteristics. It acts on various stages of the dermal healing course to hasten healing. Curcumin stimulates proliferation and remodeling stages of the skin repair process and wound contraction, which plays a crucial role in the wound healing process. ${ }^{6}$

The latest investigations demonstrated that treatment of rats with oral gavages of curcumin improved lung injury and decreased mortality, ${ }^{7}$ enhanced tendon repair, ${ }^{8}$ remarkably moderated the development of osteoarthritis (OA), ${ }^{9}$ and had an anti-hypertensive impact. ${ }^{10}$

The use of photobiomodulation (PBM) to reduce pain, inflammation, to promote wound, and to prevent tissue damage has been known for about fifty years since the invention of lasers. ${ }^{11}$ Many scientists have documented the beneficial influence of PBM regimens on skin wound healing in humans and animals. ${ }^{12-16}$

Wound healing involves synchronized activities and cellular proliferation. Approximately 9 billion dollars are spent annually in the United States to treat skin wounds. Recent researches have been conducted

Please cite this article as follows: Amini A, Soleimani H, Rezaei F, Ghoreishi SK, Chien S, Bayat M. The combined effect of photobiomodulation and curcumin on acute skin wound healing in rats. / Lasers Med Sci. 2021;12:e9. doi:10.34172/jlms.2021.09 
on the management of skin wounds. ${ }^{17}$ Despite new developments in materials for wound management, conventional treatments that rely on natural elements such as plant juices provide attractive alternatives. These treatments offer novel capabilities for curing dermal injuries, improving access to healthcare, and controlling some of the barriers associated with modern therapeutic products that include elevated costs and extensive production times. ${ }^{18}$ Limitations with current skin wound treatments show the need for secure, effective, and inexpensive formulations that can be used to treat skin injuries. Successful treatment would preferably reduce bacterial infections, control the inflammatory reaction, and concurrently increase wound strength. ${ }^{17}$

Combined treatments with different approaches and medicines have been shown to enhance the cure rates of various diseases. Therefore, these combined treatments are a focus of research among scientists today. ${ }^{19-22}$ There are few studies that assessed the impact of curcumin on healing an acute skin wound. López-Jornet et al evaluated the effect of topical curcumin on healing a $\mathrm{CO}_{2}$ laserinduced cutaneous injury in mice. These researchers determined that administration of curcumin to the $\mathrm{CO}_{2}$ laser-made cutaneous injury might be beneficial because they observed enhanced re-epithelialization after seven days. ${ }^{23}$ In another investigation, Moradi et al tested the joined impact of PBM with curcumin-loaded nanoparticles in a simulated acute skin injury mouse model. Moradi et al determined that the combination of PBM and curcumin nanoparticles reinforced the wound contraction and its tensiometric parameters. ${ }^{24}$

Although wounds in patients are closed with suture materials, an adequate amount of inherent strength should be present to maintain the wound closure. Therefore, the complete tensile strength of a wound and minimizing mechanical stressors are vital factors during the postoperative period. ${ }^{25,26}$ Nonetheless, we did not find any information in the literature that pertained to the impact of PBM plus curcumin on skin wound healing in normal animals in terms of wound closure, wound strength, and microbiological evaluating methods. In the current study, for the first time, we assayed the combined administration of PBM with curcumin in a rat model of an acute skin injury using wound closure, wound strength, and microbiological evaluating methods.

This study may support the possibility of PBM plus curcumin administration for wounds in patients, especially as management of abnormal skin repairs in large traumatic wounds, large surgical wounds, diabetic foot ulcers, pressure sores, and ischemic ulcers.

\section{Materials and Methods Animals and Study Design}

We inflicted a single skin excision on the back of each of 24 adult male Wistar rats. The rats were subsequently randomized into four groups ( $\mathrm{n}=6$ per group). Group one was the untreated control (placebo) group. Group two received pulse wave (PW) PBM. Group three was treated with curcumin. Group four received PWPBM + curcumin. Each rat was kept alone in individual rat polyethylene cages in a standard animal house and provided with standard food and water ad libitum. On days 4,7 , and 15 , we measured the wound region and conducted microbiological and tensiometric assays.

\section{Photobiomodulation}

PBM (MUSTANG 2000 with a LO7 probe; Technica Co., Russia) was administered next to the surgery and continued once per day, 6 days per week for 15 days. PBM was performed on 16 defined zones (Figure 1). ${ }^{23}$ The PBM parameters were: $1.08 \mathrm{~mW} / \mathrm{cm}^{2}, 75 \mathrm{~W}, 1.08 \mathrm{~mW}, 1 \mathrm{~cm}^{2}$, $80 \mathrm{~Hz}, 890 \mathrm{~nm}, 180 \mathrm{~ns}$, and $0.2 \mathrm{~J} / \mathrm{cm}^{2}$, with 200 seconds duration for each laser shot.

\section{Curcumin Administration}

Curcumin (40 mg/kg; Sigma Aldrich, St. Louis, MO, USA) was dissolved in $1 \mathrm{~mL}$ sesame oil. ${ }^{27}$ At first, a dose-response evaluation with 40,50 , and $60 \mathrm{mg} / \mathrm{kg}$ of curcumin was performed. A significant escalation in tensiometrical parameters of the wound healing process by $40 \mathrm{mg} / \mathrm{kg}$ curcumin was observed. So in the main study, $40 \mathrm{mg} / \mathrm{kg}$ was selected.

\section{Clinical Observations}

The rats' wounds and their weights were inspected and recorded during the experiment.

\section{Measurements of the Wound Area}

In order to compare wound closure among the study groups, we measured the wound area on days 4,7 , and 15. An image was taken of each wound area with an electronic camera, and the surface area $\left(\mathrm{mm}^{2}\right)$ was determined using Adobe Photoshop CS6 extended software. Photography could be applied to estimate the wound area. The boundaries of the wound were defined

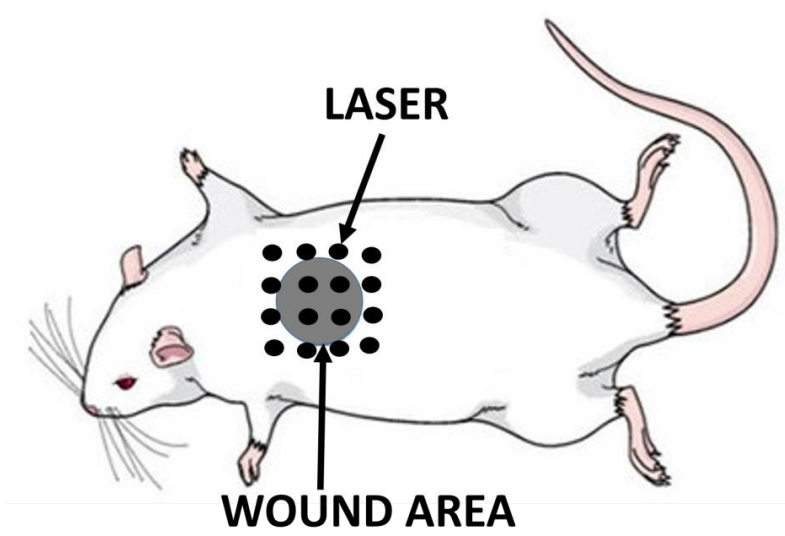

Figure 1. Schematic Illustration of the Wound Area and LaserShooting Targets. 
and marked from a digital photograph by using a mouse and a laptop. A ruler was photographed near the wound. The pictures obtained offered a stable record of both the wound size and its appearance. ${ }^{28}$

\section{Microbiological Examination}

We obtained microbial specimens from each wound on days 7 and 15 for the detection of Pseudomonas aeruginosa and Staphylococcus aureus. The samples were primarily cultured and incubated on Mueller Hinton Agar culture. Positive Staphylococcus was cultured in Mannitol salt agar for differentiating between $S$. aureus and S. epidermidis. We counted the numbers of microbes per sample as colony-forming units (CFUs). ${ }^{27}$

\section{Tensiometric Examination}

The test was clarified precisely in our former probes. ${ }^{10,13,14}$ The rats were euthanized and we obtained a standard sample (5 mm $\times 50 \mathrm{~mm}$ band) from each wound and the nearby tissue. The samples were placed in a tensile strength measuring instrument (Santam, Eng. Design Co., Ltd., Iran) that had a deformation rate of $10 \mathrm{~mm} /$ min. We reported each sample's bending stiffness $(\mathrm{MPa})$, maximum force $(\mathrm{N})$, stress high load $\left(\mathrm{N} / \mathrm{mm}^{2}\right)$, and energy absorption $(\mathrm{J})$. Bending stiffness was calculated by dividing the maximum force by the displacement of the rupture. The maximum force was measured directly from the load-deformation curve and represented the maximum tensile force applied to rupture the specimen. The stress high load was calculated as the maximum force divided by the cross-sectional area of the specimen. Energy absorption was the area under the load-deformation curve. The stress high load was calculated according to the following equation ${ }^{27}$ :

Stress high load value $=$ maximum force value $(\mathrm{N}) /$ cross-sectional area of the specimen $\left(\mathrm{cm}^{2}\right)$

\section{Statistical Analysis}

All data are expressed as mean \pm standard deviation (SD). Both one-way and two-way analysis of variances (ANOVA) and the least significant difference (LSD) tests were used for data evaluation. A $P$ value of $<0.05$ was considered to be statistically significant.

\section{Results}

All rats successfully tolerated the surgery and the treatment regimens.

\section{Wound Closure (mm2), One-Way Analysis of Variance, Day 4}

All $P$ values were related to the LSD test. The curcumin $\left(197 \pm 14 \mathrm{~mm}^{2}\right), \operatorname{PBM}\left(243 \pm 20 \mathrm{~mm}^{2}\right)$, and PBM + curcumin $\left(231 \pm 33 \mathrm{~mm}^{2}\right)$ groups showed a meaningful reinforced wound closure relative to the control group $\left(329 \pm 6.7 \mathrm{~mm}^{2}\right)(P=0.000)$. We observed that the curcumin group had meaningfully reinforced wound closure compared with the PBM $(P=0.009)$ and PBM + curcumin groups $(P=0.040)$ (Figure 2$)$.

\section{Wound Closure, Day 7}

The curcumin $\left(69 \pm 8.7 \mathrm{~mm}^{2}\right), \mathrm{PBM}\left(85 \pm 12 \mathrm{~mm}^{2}\right)$, and $\mathrm{PBM}+$ curcumin $\left(88 \pm 7.9 \mathrm{~mm}^{2}\right)$ groups meaningfully reinforced wound closure relative to the control group $\left(139.8 \pm 20.2 \mathrm{~mm}^{2}\right),(P=0.000)$. We observed that the curcumin-treated group had meaningfully reinforced wound closure relative to the $\mathrm{PBM}+$ curcumin group (LSD test, $P=0.033$ ) (Figure 2 ).

\section{Wound Closure, Day 15}

The curcumin $\left(7.5 \pm 0.57 \mathrm{~mm}^{2}, P=0.000\right)$, PBM $(8.5 \pm$ $\left.1.2 \mathrm{~mm}^{2}, P=0.000\right)$, and $\mathrm{PBM}+$ curcumin $(14.5 \pm 4.3$ $\left.\mathrm{mm}^{2}, \quad P=0.002\right)$ groups had meaningfully enhanced wound closure relative to the control group $(25 \pm 6$ $\left.\mathrm{mm}^{2}\right)$. According to the LSD test results, the curcumin group $(P=0.023)$ and PBM treated groups $(P=0.045)$ meaningfully reinforced wound closure relative to the $\mathrm{PBM}+$ curcumin group (Figure 2).

\section{Two-Way Analysis of Variance}

There were statistically significant differences between different intervals and groups. In addition, the interaction between different intervals and the group factors showed that the wound area was much smaller on day 15 relative to the other days. Moreover, the PBM and curcumin groups caused a significant reduction in the wound area on day 15 (Figure 3).

Microbiological Analysis, One-Way Analysis of Variance On day 7 , the PBM $(10.6 \pm 3.5)$, curcumin $(10.3 \pm 1.5)$, and PBM + curcumin $(26 \pm 4.5)$ groups had meaningful reductions in CFU relative to the control group $(73 \pm 3.6)$

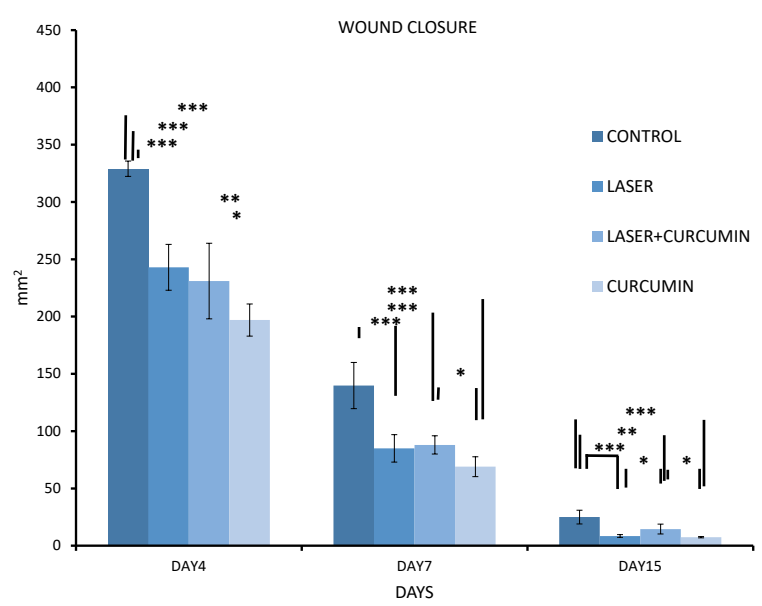

Figure 2. A Comparison of The Mean \pm SD for Wound Closures in the Study Groups on Days 4, 7, and 15 by One-Way Analysis of Variance (ANOVA) and the Least Significant Difference (LSD) Test. ${ }^{*} P<0.05$; $* * P<0.01 ; * * * P<0.001$. 


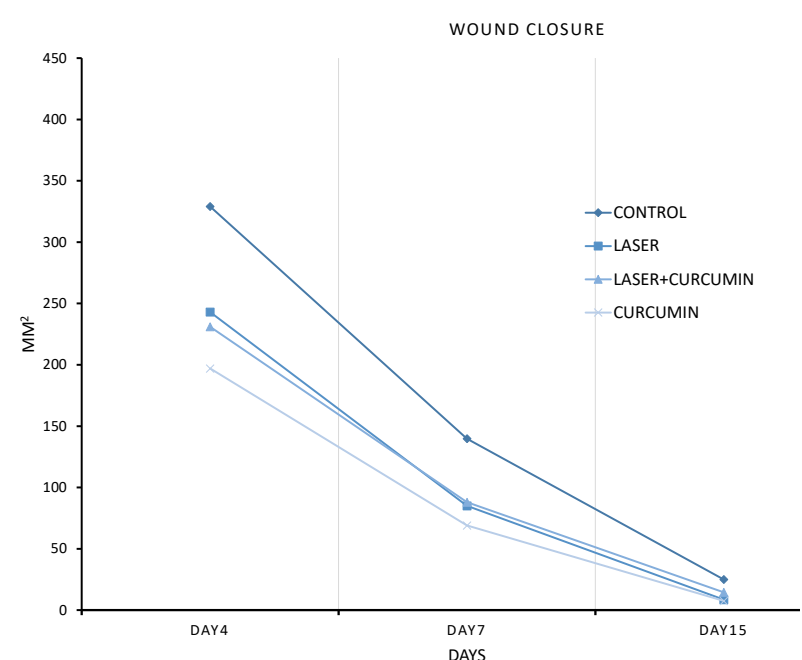

Figure 3. Two-Way Analysis of Variance (ANOVA) Shows a Significant Difference Between Different Time Points and Group Factors. We Found that Two-Way ANOVA Showed Significant Differences Regarding Number of Groups, Number of Time Points, and Interaction Effect as Follows: $F=80$, Sig $=0.000$ For the Number of Groups (4); F $=1162$, Sig $=0.000$ for the Number of Time Points (3); and F = 13.7, Sig $=0.000$ for the Interaction Effect. Consequently, there is a Meaningful Difference Between Different Time Points and Groups. The Interaction Between Different Time Points and Group Factors Shows that the Wound Area is Much Smaller on Day 15 Compared with the Other Days. The Photobiomodulation (PBM) and Curcumin Groups Caused a Significant Decrease in the Wound Area on this Day.

(all $P=0.000$ ). The PBM and curcumin groups showed a significant reduction compared to the PBM + curcumin groups (both $P=0.001)$. On day 15 , the PBM $(10 \pm 5)$, curcumin $(14 \pm 4.5)$, and PBM + curcumin $(27.3 \pm 8.3)$ groups had meaningful reductions in CFU relative to the control group $(95 \pm 6)$, (LSD test, all $P=0.000)$ (Figure $3)$. The PBM $(P=0.009)$ and curcumin $(P=0.030)$ groups showed a significant decrease in CFU compared with the $\mathrm{PBM}+$ curcumin groups.

\section{Two-Way Analysis of Variance}

Microbiological analysis indicated that the treatment with PBM alone and curcumin alone was statistically better than the combined PBM + curcumin treatment (Figure 4).

\section{Tensiometric Test}

\section{Bending Stiffnes}

Figure 5 shows the tensiometric test results. The PBM + curcumin $(19.6 \pm 2 ; P=0.002), \operatorname{PBM}(22.8 \pm 11.2$; $P=0.003)$, and curcumin $(19.1 \pm 1.3 ; P=0.006)$ groups meaningfully increased bending stiffness compared with the control group $(9.8 \pm 1.4)$ (Figure $5 \mathrm{~A})$.

\section{Maximum Force}

The PBM $(10 \pm 0.7)$ and PBM + curcumin $(9.8 \pm 0.6)$ groups meaningfully increased maximum force relative to the control group $(6.1 \pm 0.8)$ (both, $P=0.005)$ (Figure 5B).

\section{Stress High Load}

The PBM (100 \pm 7.3$)$ and PBM + curcumin $(98 \pm 6)$ groups meaningfully increased the stress high load relative to the control group (61 \pm 8.2$)$ (both, $P=0.005)$ (Figure 5C).

\section{Energy Absorption}

The PBM + curcumin ( $32 \pm 3.1 ; P=0.003)$ and PBM $(31 \pm 2.4 ; P=0.004)$ groups meaningfully raised energy absorption relative to the control group (16 \pm 3$)$.

\section{Discussion}

Wound closure and infection control are the principal objectives of wound management. There are bactericidal agents in the market that customarily reach contamination control. In contrast, wound closure remains challenging. Cell motility and migration have important roles in generating contractile force of patent wound margins and contribute to wound closure. ${ }^{29}$ Modulations of these cellular performances have been studied in the framework of wound closure; however, a beneficial tactic to obtain a wound closure has yet to be discovered. ${ }^{29}$ The establishment of successful interventions in wound management is an area of interest for investigators. ${ }^{30}$ Therefore, medically successful and cost-effective management of wounds is of utmost importance. ${ }^{31}$

Previous data of pretreatment with curcumin in excisional skin wound healing suggests that curcumin plays a potential role in wound healing. ${ }^{32-34}$ Jagetia and Rajanikant studied the effect of curcumin on radiationimpaired healing of wounds in mice. ${ }^{32-34}$ In their studies,

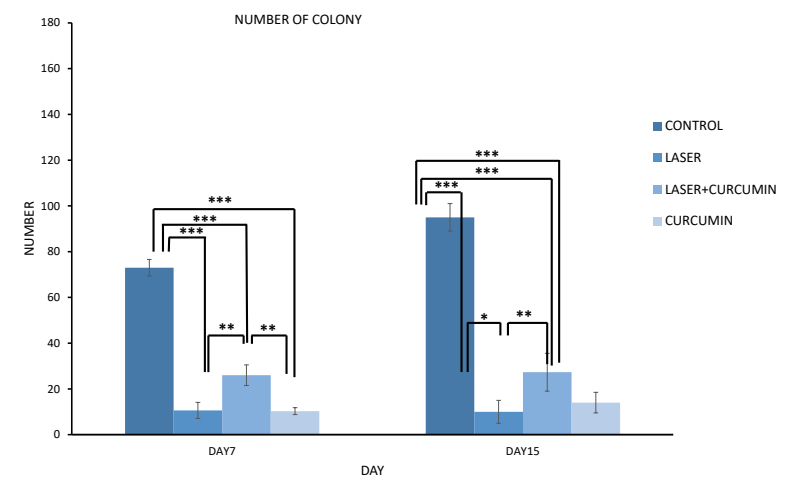

Figure 4. A Comparison Of Mean \pm SD Colony-Forming Units (CFUs) of The Study Groups on Days 4, 7, znd 15 Using One-Way Analysis of Variance (ANOVA) and the Least Significant Difference (LSD) Tests. ${ }^{*} P<0.05$; ${ }^{* *} P<0.01$; ${ }^{* * *} P<0.001$. Two-Way ANOVA Results Indicated That $F=286$ and Sig $=0.000$ for the Number of Groups (4); F = 10.5 and Sig $=0.005$ for the Number of Time Points (2); and F $=6.6$ and Sig $=0.004$ for the Interaction Effect. We Observed Meaningful Differences in CFU Among the Control and Other Groups, and also Among the Photobiomodulation (PBM) and Curcumin Groups and the PBM + Curcumin Group. 

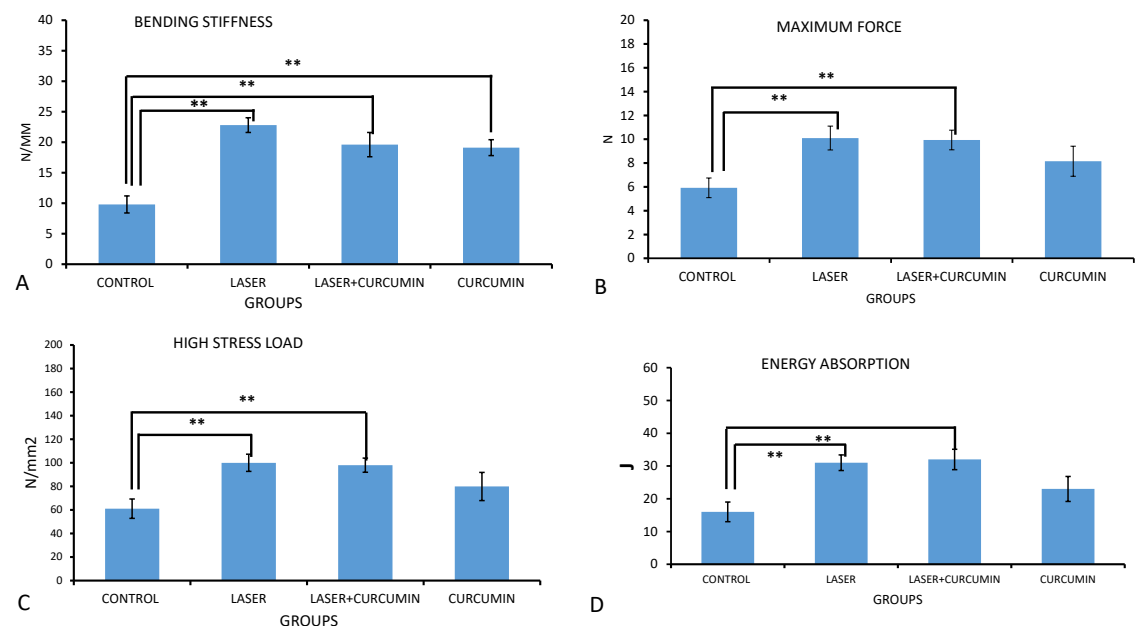

Figure 5. A Comparison of Mean \pm SD for Bending Stiffness (A), Maximum Force (B), Stress High Load (C), and Energy Absorption (D) of the Study Groups on day 15 According to One-Way Analysis of Variance (ANOVA) and the Least Significant Sifference (LSD) tests. ${ }^{* *} P<0.01$.

the skin injury repair was tested by wound closure, mean skin repair times, collagen synthesis, and histologic assessment. However, the researchers did not conduct tensiometric analyses in their studies. The tensiometric parameters of wounds are of vital importance since they indicate the probability of reopening of skin injuries. ${ }^{35}$ The patient applies pressure over a repaired wound site, which causes the wound to reopen and it should be retreated. ${ }^{35}$ Tensiometric (wound strength) parameters are considered to be the gold standard for evaluating the wound healing process. While many studies have reported the positive impact of curcumin on accelerating wound healing, ${ }^{6}$ there have been no studies about the effect of curcumin on the physical (tensiometerical) properties of repairing wounds in healthy subjects. Consequently, in the current study, we have examined the impact of curcumin on tensiometerical properties of repairing wounds. Our statistical analysis showed that although curcumin did not show a positive effect on wound strength, PBM and $\mathrm{PBM}+$ curcumin groups meaningfully increased wound strength compared to the control group (both, $P=0.005$, Figure 5C). It seems the administration of curcumin alone could not accelerate the wound healing process in healthy rats. Moreover, curcumin administration could not improve the beneficial influence of PBM on repairing tissue. Interestingly, in another study, Moradi et al concluded that the topical administration of curcumin nanoparticles, PBM, and PBM+ curcumin nanoparticles increase wound strength. ${ }^{24}$ We hypothesized that adding nanoparticles to curcumin increases its absorption in a wound bed compared to the absorption of curcumin alone in the gastrointestinal tract in the current study. Consequently, the positive impact of the curcumin + nanoparticles alone and curcumin + nanoparticles plus $\mathrm{PBM}$ on increasing wound strength of repairing tissue was observed.
Some improvements in the tensiometric properties after $\mathrm{PBM}^{16,36,37}$ suggested an improved wound healing process. $^{35}$ In the current study, curcumin did not meaningfully enhance the wound tensiometric properties. Bayat et al reported that PBM $(780 \mathrm{~nm}, 2336 \mathrm{~Hz}, 2 \mathrm{~J} /$ $\mathrm{cm}^{2}$ ) meaningfully increased the fibroblasts, blood vessel sections, and high stress load of a wound bed. ${ }^{16}$ Vasilenko et al reported that several power densities of PBM (635 $\mathrm{nm}, 670 \mathrm{~nm}, 5 \mathrm{~J} / \mathrm{cm}^{2}$ ) improved wound strength. ${ }^{31}$ Bisht et al observed that wound strength, early reepithelization, fibroblast number, and neovascularization improved in the laser-treated wounds. ${ }^{32}$ Our findings supported the results of these studies. ${ }^{16,36,37}$

In the current study, the reduction in tensiometric properties of the excisional wounds in the curcumintreated rats was likely attributed to the low doses of curcumin. Recently, Jiang et al examined the influence of curcumin on tendon repair in rats. The test group received $100 \mathrm{mg} / \mathrm{kg}$ body weight of curcumin via oral gavage. The researchers found that curcumin remarkably enhanced the repairing characteristics as shown by widespread deposition of well-organized collagen fibrils, reduced malondialdehyde levels, and improved tensiometric properties of the repaired tendon. ${ }^{8}$ On the other hand, our pilot study showed a significant escalation in tensiometric properties of an incisional skin wound model in normal rats treated with $40 \mathrm{mg} / \mathrm{kg}$ curcumin when evaluated 15 days after surgery.

The results of experiments on the effects of PBM on microbial flora in an in vitro ${ }^{38,39}$ and an in vivo model ${ }^{40}$ are inconsistent. PBM increased the wound closure of burns in animals. There was no significant difference in $S$. epidermidis, $S$. aureus, and $P$. aeruginosa growth between the study groups. ${ }^{40}$ Some studies have shown the beneficial impact of PBM on the inhibition of bacterial growth in vitro ${ }^{41}$ and in vivo. $\mathrm{PBM}$ with dissimilar wavelengths and 
energy densities enhanced the wound healing course in infested and non-infested injuries. ${ }^{15,16,42-45}$ Ezzati et al examined the effect of PBM $(890 \mathrm{~nm}, 3000 \mathrm{~Hz}$, and 2.3 and $11.7 \mathrm{~J} / \mathrm{cm}^{2}$ ) during two probes in rats that had second- and third-degree burns. ${ }^{15,44}$ In the first study, they determined that the administration of $11.7 \mathrm{~J} / \mathrm{cm}^{2}$ PBM meaningfully decreased the incidence of $S$. aureus and meaningfully increased the wound-closure rate compared with the placebo in the second-degree burns. ${ }^{15}$ In the second study, the researchers reported that the incidence of $S$. epidermidis meaningfully decreased and meaningfully increased the wound-closure rate after the administration of $11.7 \mathrm{~J} / \mathrm{cm}^{2} \mathrm{PBM}^{44}$

Based on our results and data reported from other studies, ${ }^{15,44}$ the administration of PBM on a wound is crucial and a PBM protocol with proper energy density is necessary to achieve maximum bactericidal effects along with enhanced wound healing.

In many illness courses, the course of happenings contributing to wound healing could be negatively affected, resulting in chronic, non-healing wounds that subject the patient and community to significant discomfort, distress, and bills. The healing of a skin injury needs numerous elements to corporate together in concert, and wound dressings and treatments have developed significantly to overcome probable blocks to wound healing, ranging from infection to hypoxia. Even ideally, repairing tissue does not ever grasp its pre-injured power and many abnormal healing states could result in chronic wounds. ${ }^{46}$ Wound care is a major healthcare expenditure. Treatment of burns, surgical and trauma wounds, and skin wounds is a major medical challenge with current therapies largely focused on supportive care measures. ${ }^{47}$ Consequently, there is a trend among researchers to apply several beneficial agents for accelerating wound healing at the same time. ${ }^{48-50}$

We concluded that the PBM and PBM + curcumin treated groups meaningfully accelerated wound healing of an acute skin wound in rats. The results of the PBMtreated group were statistically more effective than the curcumin alone and PBM + curcumin-treated groups.

The importance of wound healing and the benefits of PBM and curcumin are documented. Because of the limited studies that have evaluated the impact of PBM and curcumin on wound healing, we suggest that additional studies assess the impact of different curcumin administration models such as curcumin nanoparticles to determine the best effect on non-healing wounds such as diabetic wounds in animal models and patients.

\section{Ethical Considerations}

The Institutional Review Board of Shahid Beheshti University of Medical Sciences, Tehran, Iran approved this study (protocol: 9124).

\section{Conflict of Interests}

The authors declare that there are no conflicts of interest.

\section{Acknowledgments}

This work was a self-funded research study and the authors received no financial support for this paper. Dr. Sufan Chien was supported in part by NIH grant DK105692.

\section{References}

1. Weiser TG, Haynes AB, Molina G, Lipsitz SR, Esquivel MM, Uribe-Leitz T, et al. Estimate of the global volume of surgery in 2012: an assessment supporting improved health outcomes. Lancet. 2015;385(Suppl 2):S11. doi: 10.1016/ S0140-6736(15)60806-6.

2. Babaei S, Bayat M. Pentoxifylline accelerates wound healing process by modulating gene expression of MMP-1, MMP-3, and TIMP-1 in normoglycemic rats. J Invest Surg. 2015;28(4):196-201. doi: 10.3109/08941939.2014.1002642.

3. Ammon HP, Wahl MA. Pharmacology of Curcuma longa. Planta Medica. 1991;57(1):1-7. doi: 10.1055/s-2006960004.

4. Amalraj A, Pius A, Gopi S, Gopi S. Biological activities of curcuminoids, other biomolecules from turmeric and their derivatives- A review. J Tradit Complement Med. 2017;7(2):205-33. doi: 10.1016/j.jtcme.2016.05.005.

5. Chainani-Wu N. Safety and anti-inflammatory activity of curcumin: a component of tumeric (Curcuma longa). J Altern Complement Med. 2003;9(1):161-8. doi: 10.1089/107555303321223035.

6. Akbik D, Ghadiri M, Chrzanowski W, Rohanizadeh R. Curcumin as a wound healing agent. Life Sci. 2014;116(1):17. doi: 10.1016/j.lfs.2014.08.016.

7. Xu Y, Ge L, Abdel-Razek O, Jain S, Liu Z, Hong Y, et al. Differential susceptibility of human Sp-B genetic variants on lung injury caused by bacterial pneumonia and the effect of a chemically modified curcumin. Shock. 2016;45(4):37584. doi: 10.1097/SHK.0000000000000535.

8. Jiang D, Gao P, Lin H, Geng H. Curcumin improves tendon healing in rats: a histological, biochemical, and functional evaluation. Connect Tissue Res. 2016;57(1):20-7. doi: 10.3109/03008207.2015.1087517.

9. Zhang Z, Leong DJ, Xu L, He Z, Wang A, Navati M, et al. Curcumin slows osteoarthritis progression and relieves osteoarthritis-associated pain symptoms in a posttraumatic osteoarthritis mouse model. Arthritis Res Ther. 2016;18(1):128. doi: 10.1186/s13075-016-1025-y.

10. Yao Y, Wang W, Li M, Ren H, Chen C, Wang J, et al. Curcumin exerts its anti-hypertensive effect by downregulating the AT1 receptor in vascular smooth muscle cells. Sci Rep. 2016;6:25579. doi: 10.1038/srep25579.

11. Farivar S, Malekshahabi T, Shiari R. Biological effects of low level laser therapy. J Lasers Med Sci. 2014;5(2):58-62.

12. Percival SL, Francolini I, Donelli G. Low-level laser therapy as an antimicrobial and antibiofilm technology and its relevance to wound healing. Future Microbiol. 2015;10(2):255-272. doi: 10.2217/fmb.14.109.

13. de Medeiros ML, Araújo-Filho I, da Silva EMN, de Sousa 
Queiroz WS, Soares CD, de Carvalho MGF, et al. Effect of low-level laser therapy on angiogenesis and matrix metalloproteinase-2 immunoexpression in wound repair. Lasers Med Sci. 2017;32(1):35-43. doi: 10.1007/s10103016-2080-y.

14. Hussein AJ, Alfars AA, Falih MA, Hassan AN. Effects of a low level laser on the acceleration of wound healing in rabbits. N Am J Med Sci. 2011;3(4):193-7. doi: 10.4297/ najms.2011.3193.

15. Ezzati A, Bayat M, Khoshvaghti A. Low-level laser therapy with a pulsed infrared laser accelerates second-degree burn healing in rat: a clinical and microbiologic study. Photomed Laser Surg. 2010;28(5):603-11. doi: 10.1089/pho.2009.2544.

16. Bayat M, Azari A, Golmohammadi MG. Effects of 780-nm low-level laser therapy with a pulsed gallium aluminum arsenide laser on the healing of a surgically induced open skin wound of rat. Photomed Laser Surg. 2010;28(4):46570. doi: 10.1089/pho.2008.2450.

17. Sinno H, Prakash S. Complements and the wound healing cascade: an updated review. Plast Surg Int. 2013;2013:146764. doi: 10.1155/2013/146764.

18. Pereira RF, Bartolo PJ. Traditional therapies for skin wound healing. Adv Wound Care (New Rochelle). 2016;5(5):20829. doi: 10.1089/wound.2013.0506.

19. Hatori K, Camargos GV, Chatterjee M, Faot F, Sasaki K, Duyck J, et al. Single and combined effect of highfrequency loading and bisphosphonate treatment on the bone micro-architecture of ovariectomized rats. Osteoporos Int. 2015;26(1):303-13. doi: 10.1007/s00198-014-2857-4.

20. Camargos G, Bhattacharya P, van Lenthe GH, Del Bel Cury AA, Naert I, Duyck J, et al. Mechanical competence of ovariectomy-induced compromised bone after single or combined treatment with high-frequency loading and bisphosphonates. Sci Rep. 2015;5:10795. doi: 10.1038/ srep10795.

21. Sasaki H, Miyakoshi N, Kasukawa Y, Maekawa S, Noguchi $\mathrm{H}$, Kamo K, et al. Effects of combination treatment with alendronate and vitamin $\mathrm{K}_{2}$ on bone mineral density and strength in ovariectomized mice. J Bone Miner Metab. 2010;28(4):403-9. doi: 10.1007/s00774-009-0148-5.

22. Ringe JD. [Combination treatment in osteoporosis. Basic treatment plus specific osteoporosis medication]. Med Monatsschr Pharm. 2009;32(4):137-40. [German].

23. López-Jornet P, Camacho-Alonso F, Jiménez-Torres MJ, Orduña-Domingo A, Gómez-García F. Topical curcumin for the healing of carbon dioxide laser skin wounds in mice. Photomed Laser Surg. 2011;29(12):809-814. doi: 10.1089/pho.2011.3004.

24. Moradi A, Kheirollahkhani Y, Fatahi P, Abdollahifar MA, Amini A, Naserzadeh P, et al. An improvement in acute wound healing in mice by the combined application of photobiomodulation and curcumin-loaded iron particles. Lasers Med Sci. 2019;34(4):779-791. doi: 10.1007/s10103018-2664-9.

25. Ireton JE, Unger JG, Rohrich RJ. The role of wound healing and its everyday application in plastic surgery: a practical perspective and systematic review. Plast Reconstr Surg Glob Open. 2013;1(1):e10-e19. doi: 10.1097/ GOX.0b013e31828ff9f4.

26. Guo S, Dipietro LA. Factors affecting wound healing. J Dent Res. 2010;89(3):219-229. doi: 10.1177/0022034509359125.
27. Soleimani H, Amini A, Taheri S, Sajadi E, Shafikhani $S$, Schuger LA, et al. The effect of combined photobiomodulation and curcumin on skin wound healing in type I diabetes in rats. J Photochem Photobiol B. 2018;181:23-30. doi: 10.1016/j.jphotobiol.2018.02.023.

28. Chang AC, Dearman B, Greenwood JE. A comparison of wound area measurement techniques: visitrak versus photography. Eplasty. 2011;11:e18.

29. Lin A, Hokugo A, Nishimura I. Wound closure and wound management: A new therapeutic molecular target. Cell Adh Migr. 2010;4(3):396-9. doi: 10.4161/cam.4.3.11917.

30. Sood A, Granick MS, Tomaselli NL. Wound dressings and comparative effectiveness data. Adv Wound Care (New Rochelle). 2014;3(8):511-29. doi: 10.1089/ wound.2012.0401.

31. Günter CI, Machens HG. New strategies in clinical care of skin wound healing. Eur Surg Res. 2012;49(1):16-23. doi: $10.1159 / 000339860$.

32. Jagetia GC, Rajanikant GK. Effect of curcumin on radiation-impaired healing of excisional wounds in mice. J Wound Care. 2004;13(3):107-9. doi: 10.12968/ jowc.2004.13.3.26589.

33. Jagetia GC, Rajanikant GK. Curcumin treatment enhances the repair and regeneration of wounds in mice exposed to hemibody $\gamma$-irradiation. Plast Reconstr Surg. 2005;115(2):515-28. doi: 10.1097/01. prs.0000148372.75342.d9.

34. Jagetia GC, Rajanikant GK. Acceleration of wound repair by curcumin in the excision wound of mice exposed to different doses of fractionated $\gamma$ radiation. Int Wound J. 2012;9(1):76-92. doi: 10.1111/j.1742-481X.2011.00848.x.

35. Reddy GK, Stehno-Bittel L, Enwemeka CS. Laser photostimulation accelerates wound healing in diabetic rats. Wound Repair Regen. 2001;9(3):248-55. doi: 10.1046/j.1524-475x.2001.00248.x.

36. Vasilenko T, Slezák M, Kovác I, Bottková Z, Jakubco J, Kostelníková M, et al. The effect of equal daily dose achieved by different power densities of low-level laser therapy at 635 and $670 \mathrm{~nm}$ on wound tensile strength in rats: a short report. Photomed Laser Surg. 2010;28(2):281-3. doi: 10.1089/pho.2009.2489.

37. Bisht D, Mehrotra R, Singh PA, Atri SC, Kumar A. Effect of helium-neon laser on wound healing. Indian J Exp Biol. 1999;37(2):187-9.

38. Pereira PR, de Paula JB, Cielinski J, Pilonetto M, Von Bahten LC. Effects of low intensity laser in in vitro bacterial culture and in vivo infected wounds. Rev Col Bras Cir. 2014;41(1):49-55. doi: 10.1590/s0100-69912014000100010.

39. Nussbaum EL, Lilge L, Mazzulli T. Effects of 630-, 660, 810-, and 905-nm laser irradiation delivering radiant exposure of $1-50 \mathrm{~J} / \mathrm{cm} 2$ on three species of bacteria in vitro. J Clin Laser Med Surg. 2002;20(6):325-33. doi: 10.1089/104454702320901116.

40. Vasheghani MM, Bayat M, Dadpay M, Habibie M, Rezaei F. Low-level laser therapy using $80-\mathrm{Hz}$ pulsed infrared diode laser accelerates third-degree burn healing in rat. Photomed Laser Surg. 2009;27(6):959-64. doi: 10.1089/pho.2008.2366.

41. Masson-Meyers DS, Bumah VV, Biener G, Raicu V, Enwemeka CS. The relative antimicrobial effect of blue $405 \mathrm{~nm} \mathrm{LED}$ and blue $405 \mathrm{~nm}$ laser on methicillin- 
resistant Staphylococcus aureus in vitro. Lasers Med Sci. 2015;30(9):2265-71. doi: 10.1007/s10103-015-1799-1.

42. Silva DC, Plapler H, Costa MM, Silva SR, Sá MC, Silva BS. Low level laser therapy (AlGaInP) applied at $5 \mathrm{~J} / \mathrm{cm} 2$ reduces the proliferation of Staphylococcus aureus MRSA in infected wounds and intact skin of rats. An Bras Dermatol. 2013;88(1):50-5. doi: 10.1590/s0365-05962013000100005.

43. Santos NR, de M Sobrinho JB, Almeida PF, Ribeiro AA, Cangussú MC, dos Santos JN, et al. Influence of the combination of infrared and red laser light on the healing of cutaneous wounds infected by Staphylococcus aureus. Photomed Laser Surg. 2011;29(3):177-82. doi: 10.1089/ pho.2009.2749.

44. Ezzati A, Bayat M, Taheri S, Mohsenifar Z. Low-level laser therapy with pulsed infrared laser accelerates thirddegree burn healing process in rats. J Rehabil Res Dev. 2009;46(4):543-54. doi: 10.1682/jrrd.2008.09.0121.

45. Shomina SA, Bogatov VV, Chervinets VM. [Clinicalmicrobiological evaluation of the efficacy of combined use of chitosan, low intensity laser radiation and photosensitizer in treatment of patients with acute suppurative maxillofacial periostitis]. Stomatologiia (Mosk). 2005;84(3):23-6. Russian.

46. Han G, Ceilley R. Chronic wound healing: a review of current management and treatments. Adv Ther. 2017;34(3):599-610. doi: 10.1007/s12325-017-0478-y.

47. Lin PH, Sermersheim M, Li H, Lee PHU, Steinberg SM, Ma J. Zinc in wound healing modulation. Nutrients. 2017;10(1):16. doi: 10.3390/nu10010016.

48. Wu DQ, Zhu J, Han H, Zhang JZ, Wu FF, Qin XH, et al. Synthesis and characterization of arginine-NIPAAm hybrid hydrogel as wound dressing: In vitro and in vivo study. Acta Biomater. 2018;65:305-316. doi: 10.1016/j. actbio.2017.08.048

49. Zhao X, Sun X, Yildirimer L, Lang Q, Lin ZY, Zheng $\mathrm{R}$, et al. Cell infiltrative hydrogel fibrous scaffolds for accelerated wound healing. Acta Biomater. 2017;49:66-77. doi: 10.1016/j.actbio.2016.11.017.

50. Choi J, Park YG, Yun MS, Seol JW. Effect of herbal mixture composed of Alchemilla vulgaris and Mimosa on wound healing process. Biomed Pharmacother. 2018;106:326-332. doi: 10.1016/j.biopha.2018.06.141. 